\title{
Fiebre aftosa en seres humanos. Un caso en Chile
}

\author{
Patricio Berríos E.
}

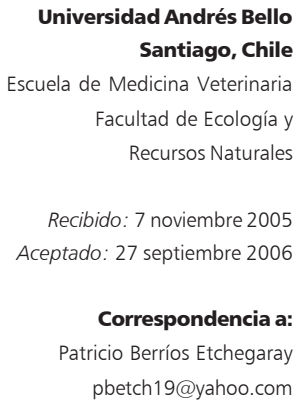

pbetch19@yahoo.com

\section{Foot and mouth disease in human beings. A human case in Chile}

Foot and mouth disease (FMD) of cattle can cause a significant economic burden and is thus for one of the most feared of cattle disease. FMD is endemic in South America, Africa, Asia and parts of Europe and it is characterized by vesicles in different locations, mainly mouth, feet and teats leading to severe animal weakness. Currently most countries refuse to import livestock and livestock products from FMD areas. North and Central America are currently free of FMD and Chile is free of FMD from 1987. Approximately 40 cases of human infection with FMD virus have been reported, mostly in Europe, and confirmed by virus isolation and the detection of a specific immune response. We discuss the case of a human infection with FMD virus occurred in Chile in 1961 and other relevant cases reported. FMD does not currently present a threat to public health. Even though the FMD virus has the potential to mutate rapidly and emerge as a significant human zoonosis; the rarity of the disease in humans despite a long history of close contact with FMD infected animals suggests that the risk is highly improbable. Then FMD should not be managed as a zoonosis.

Key words: foot and mouth disease, Chile.

Palabras claves: Fiebre aftosa, Chile.

\section{Introducción}

$\mathrm{L}$ a fiebre aftosa (FAf) es una enfermedad infecciosa viral que afecta a los animales biungulados. La FAf es muy contagiosa y se presenta con alta morbilidad y baja mortalidad. Las pérdidas económicas consecutivas a la infección de animales se deben, principalmente, a la disminución de la producción de leche en vacas infectadas y al retardo en el crecimiento del ganado de carne. Su distribución es mundial. El primer caso probable de FAf fue descrito en Italia por Francastorious en 1514. El primer diagnóstico de laboratorio de FAf en nuestro país se realizó en Chillán en 1942. Chile está libre de esta enfermedad trans-fronteriza desde $1987^{1}$.

El virus aftoso se clasifica en el género Aphtovirus de la familia Picornaviridae; presenta siete tipos serológicos y más de 65 subtipos antigénicamente diferentes. El virus aftoso infecta naturalmente a los animales de pezuñas hendidas: porcinos, bovinos, ovinos, caprinos, venados y rumiantes salvajes como el búfalo de agua, impala y kudú en África, y camélidos sudamericanos. Las lesiones vesiculares se encuentran preferentemente en el hocico y en las patas de los animales. Los cerdos son altamente susceptibles al virus aftoso, por lo que han sido utilizados como animales centinelas; los equinos y roedores son resistentes en forma natural.
La FAf es una enfermedad infecciosa viral animal, siendo el hombre un huésped accidental que, rara vez, se infecta y enferma; sin embargo, se suele considerar a esta enfermedad como una zoonosis aunque su ocurrencia en el Hombre es ocasional, especialmente si se compara de manera proporcional con la amplia distribución geográfica y alta incidencia que tiene en los animales biungulados, incluso si se considera las frecuentes oportunidades de contagio a las que están expuestos los seres humanos en el campo o en el laboratorio ${ }^{1}$.

En Inglaterra, en el año 2001, la FAf ocasionó más de 70 brotes que afectaron porcinos, bovinos y ovinos, lo que obligó al sacrificio de unos 500.000 animales causando cuantiosas pérdidas económicas. La detección de un caso comprobado de FAf en un ser humano alarmó a las autoridades de salud pública debido a que la cepa actuante correspondía a la cepa Pan-Asia tipo "O", considerada por la OMS como muy agresiva. Esta cepa pandémica, prácticamente, desplazó a las otras cepas del virus aftoso que actuaban en el último decenio del siglo XX, expandiéndose desde India en 1990 por todo Asia hasta llegar al continente europeo y, específicamente, a Inglaterra donde se presentó en Essex en febrero de $2001^{1}$.

Fiebre aftosa en seres humanos. En el hombre exis- 
ten diversas patologías que manifiestan vesículas en boca, manos y pies, como es el caso de los virus Coxsackie A16 (CV-A16), enterovirus 71 (EV-71), virus de la estomatitis vesicular (un rhabdovirus) y el virus herpes simplex tipo 1, que pueden confundirse con la FAf $^{2}$. Por esta razón, el diagnóstico clínico no tiene un valor definitivo y es necesaria la confirmación de laboratorio, ya sea por el aislamiento del virus y su tipificación o por la detección de anticuerpos séricos específicos.

La FAf en seres humanos se caracteriza por una fase inicial de fiebre, cefalea, anorexia y taquicardia; las vesículas son de tamaño variable, aparecen en las manos, pies y boca y si no hay sobreinfección bacteriana, el paciente se recupera en una a dos semanas. El período de incubación es de uno a diez días. En algunos casos no se han observado síntomas ni lesiones $^{3-9}$.

La primera sugerencia de infección por el virus aftoso en humanos fue reportada por Valentini, en Alemania, en 1695. En 1834, un médico cirujano de apellido Hertwig, se infectó deliberadamente bebiendo leche proveniente de vacas con FAf.

La mayor parte de los casos registrados en la literatura médica, con diagnóstico de laboratorio, fueron identificados en Europa. De hecho, sólo existen unos 40 casos confirmados en el laboratorio por aislamiento e identificación del virus o por la detección de anticuerpos séricos en pacientes recuperados de la infección, siendo el tipo "O" del virus aftoso el que más se ha aislado desde humanos y raramente el "A" (Tabla 1).

Las fuentes más frecuentes de contagio han sido accidentes de laboratorio y por ordeño de vacas enfermas de FAf. Existen pocos registros de FAf causada por la ingestión de leche cruda, por contagio en mataderos, por manejo de animales enfermos o durante la recolección de materiales infecciosos. No se han comprobado casos de FAf debidos a la ingestión de carne y productos cárnicos. Algunas evidencias circunstanciales sugieren que los niños pueden enfermar al ingerir leche cruda proveniente de vacas con FAf $^{10}$.

En 1970 se aisló virus aftoso desde lavados con hisopos de las fosas nasales en 10 hombres que trabajaban en estrecho contacto con cerdos infectados. El título infeccioso de los virus aislados luego del contacto inicial fue de $10^{2,1}$ a $10^{3,7}$ DI50; después de $2 \frac{1}{2}$ a $4 \frac{1}{2}$ horas del contacto, los títulos bajaron sensiblemente en ocho de los individuos afectados, mientras que dos fueron negativos.

En Alemania, en 1962, se describió un caso de interés infectológico cuando un paciente se infectó con virus aftoso tipo "O" habiéndose infectado dos años antes con el tipo "C", situación explicada por la no existencia de reacción cruzada entre los siete tipos del virus aftoso, y por la escasa duración de la inmunidad anti-aftosa, concepto inmunológico válido al menos en bovinos ${ }^{10}$. Otro caso interesante es el de un paciente que durante un brote de fiebre aftosa en bovinos desarrolló vesículas en la palma y dorso de las manos, y en los pies, que sanaron dos semanas después, para reaparecer luego de tres días y cinco meses, probablemente debido a re-infección; en ambos casos el enfermo sanó a los 15 días $^{10}$.

En 1967, se describió el caso de un médico veterinario alemán que se infectó con el virus aftoso al recoger linfa de una vesícula de un cerdo, desarrollando vesículas en las manos y los pies; el virus aftoso se aisló por inoculación en ratones lactantes y fue tipificado como tipo "C" en la prueba de fijación del complemento. El diagnóstico fue confirmado por la presencia de anticuerpos en el suero del paciente contra el tipo "C"11.

Un caso de FAf confirmado, y descrito con más detalles, se detectó en el brote de FAf ocurrido en Inglaterra en 1967, en que se aisló el virus aftoso tipo "O" desde un trabajador llamado Robert Brewis de

\begin{tabular}{|c|c|c|c|c|}
\hline Año & Autor & $\begin{array}{c}\text { Tipo } \\
\text { de virus }\end{array}$ & País & Fuente de Infección \\
\hline 1929 & Trautwein & A & Alemania & Accidente de trabajo \\
\hline 1934 & von Scheltz & $\mathrm{O}$ & Alemania & $?$ \\
\hline 1938 & Rinjard & $\mathrm{O}$ & Francia & Ordeño \\
\hline 1938 & Magnusson & 0 & Suecia & Animales enfermos \\
\hline 1938 & Flaum & $\mathrm{O}$ & Suecia & Ordeño \\
\hline 1941 & Stenstrom & $\mathrm{O}$ & Suecia & Ordeño \\
\hline 1950 & Holm & $\mathrm{O}$ & Países Bajos & $?$ \\
\hline 1951 & Wahl & C & Alemania & Ordeño \\
\hline 1954 & Czarnowski & C & Polonia & $?$ \\
\hline 1955 & Geiger & C & Alemania & Accidente de laboratorio \\
\hline 1959 & Garbe & C & Alemania & Accidente de laboratorio \\
\hline 1960 & Meléndez & $\mathrm{O}$ & Chile & Accidente de laboratorio \\
\hline 1962 & Pilz & C & Alemania & Accidente de laboratorio \\
\hline 1962 & Pilz & $\mathrm{O}$ & Alemania & Accidente de laboratorio \\
\hline 1963 & Schwann & C & Polonia & Ordeño \\
\hline 1964 & Heinig & C & Alemania & $?$ \\
\hline 1964 & Kobuclewitcz & C & Polonia & Ingestión de leche cruda \\
\hline 1965 & Pilz & $\mathrm{O}$ & Alemania & Accidente de laboratorio \\
\hline 1967 & Salazhov & A & Rusia & Ingestión de leche cruda y ordeño \\
\hline 1967 & Elssner & C & Alemania & Colección de material en terreno \\
\hline 1967 & Armstrong & $\mathrm{O}$ & Inglaterra & Animal enfermo \\
\hline 2001 & Bohn & 0 & Inglaterra & Animal enfermo \\
\hline
\end{tabular}


Yetlington en Northumberland, que presentaba una temperatura moderadamente alta, odinofagia, vesículas en las palmas de sus manos, y equimosis en su lengua. El diagnóstico fue confirmado por seroconversión ${ }^{4}$.

El último caso de FAf en humanos fue descrito en Cumbria, en el Norte de Inglaterra, durante el brote de FA ocurrido en el año 2001 y causado por el tipo “0”. Un trabajador agrícola cargaba los restos en descomposición de una vaca para ser incinerada y al explotar el animal, el hombre recibió fluidos infectados en su boca ${ }^{6}$.

Un caso de fiebre aftosa en un ser humano en Chile. En 1961, se describió el aislamiento de virus aftoso tipo "O" desde vesículas ubicadas en la palma de una mano de una ayudante técnico de la Sección Microbiología Veterinaria del Instituto Bacteriológico de Chile, quien se infectó mientras inoculaba el virus en ratones lactantes. La paciente presentó un alza térmica al cuarto día de la infección, cefalea, náuseas y malestar general, síntomas y signos que duraron entre ocho y diez días. Desde las lesiones vesiculares ubicadas en la palma de la mano afectada, se tomaron muestras de líquido vesicular las que se inocularon en cultivos celulares. El virus aislado fue tipificado como tipo "O" mediante seroneutralización con antisueros específicos. El suero obtenido de la paciente a los cuatro y 18 días después de la infección, presentó, inicialmente, un índice neutralizante (frente al serotipo "O") de 0 y 1,8 , el que luego de dos semanas aumentó a 5,62 y 3,82. La reactividad serológica para los antígenos " $\mathrm{A}$ " $\mathrm{y}$ " $\mathrm{C}$ " fue negativa ${ }^{13}$.

\section{¿Es la fiebre aftosa una zoonosis?}

La FAf ha sido considerada como una zoonosis aunque su ocurrencia es más bien rara en los seres humanos, los que son poco susceptibles al virus aftoso. La FAf es una infección animal en que el ser humano sería un huésped accidental que rara vez se infecta. Según Acha y Szifres $(1986)^{14}$, se considera como zoonosis a una enfermedad infecciosa transmisible, en condiciones naturales, entre animales vertebrados y el hombre. Sin embargo, estos autores definen a la FAf como una zoonosis, aunque Pedro Acha, alguna vez reconoció que lo había hecho sólo con el fin de lograr interesar a las autoridades sanitarias para que cooperaran con fondos en la lucha contra la FAf en Perú ${ }^{14}$.

Son escasos los reportes de FAf en seres humanos, número que no va más allá de 40 , cifra insignificante comparada con el alto número de animales que se han enfermado o han sido sacrificados en los grandes brotes de FAf que han ocurrido y que siguen ocurriendo en el mundo ${ }^{1}$.

La mayoría de los casos descritos, avalados por un diagnóstico de laboratorio, presentan como fuente de infección accidentes de laboratorio e infección por ordeño de vacas enfermas de FAf. Son escasos los registros de enfermedad por ingestión de leche cruda, infección en mataderos y por manejo de animales enfermos, especialmente durante la recolección de material infeccioso para su diagnóstico. Nunca se ha comprobado la transmisión entre seres humanos. Tampoco se han descrito casos de FAf en seres humanos debidos a la ingestión de carne y productos cárnicos ${ }^{15-20}$. Además pareciera ser que ha existido una cierta confusión en el diagnóstico de FAf en humanos, debido a la similitud de los síntomas que exhibe la fiebre aftosa de los ungulados, en inglés "Foot and mouth disease" causada por el virus aftoso, y la enfermedad de las manos, pies y boca, en inglés "Hand, foot and mouth disease" causada por distintos representantes de los enterovirus $^{21,22}$.

En nuestro país no existen referencias científicas sobre los niños que presentaban lesiones vesiculares bucales después de haber ingerido leche bovina, en una época en que la FAf era endémica en la zona central. Algunos médicos la llamaron FAf, bien pudieron denominarla estomatitis vesicular o estomatitis herpética.

Según Bauer $(1997)^{23}$, no cabe la menor duda de que la FAf es una zoonosis; sin embargo, Schrijver et al $(1997)^{24}$ opinan que la FAf no es una zoonosis. Donaldson y Knowles $(2001)^{3}$ del Laboratorio de Pirbright del Instituto de Salud Animal, Pirbright, Surrey, Reino Unido, manifiestan que las últimas declaraciones sobre el riesgo de que el hombre se contagie con el virus de la FAf, han sido más bien conflictivas y confusas". Tendríamos que agregar, cautelosamente, que también muchas de ellas han sido equivocadas y tendenciosas.

\section{Resumen}

La fiebre aftosa se presenta en los biungulados, siendo el cerdo el animal más susceptible. La infección de estos animales lleva a cuantiosas pérdidas económicas por disminución de la producción de leche o carne. En la actualidad esta enfermedad constituye una plaga que causa serios trastornos en el comercio pecuario mundial y se la considera como una enfermedad trans-fronteriza. Chile está libre se esta enfermedad desde 1987. La fiebre aftosa en seres humanos ha sido descrita principalmente en Europa, habiéndose confirmado, aproximadamente, unos 40 casos por aislamiento viral y detección de anticuerpos específicos. Se describen los principales casos de fiebre aftosa en seres humanos descritos en la literatura científica, incluyendo un caso ocurrido en Chile en 1961. Se discute la importancia de esta enfermedad en seres humanos y se cuestiona el planteamiento de que es una zoonosis. 


\section{Referencias}

1.- Berríos P. Actualización sobre fiebre aftosa. Chile Agrícola 2001; 26: 79-81.

2.- Berríos P. Fiebre aftosa en humanos. ¿Es la fiebre aftosa una zoonosis? Tecno Vet 2004; 10: 19-23.

3.- Sellers R F, Donaldson A I, Herniman K A J. Inhalation, persistence and dispersal of foot and mouth disease virus by man. J Hyg 1970; 68: $565-73$.

4.- Donaldson A, Knowles N. Foot and mouth disease in man. Vet Rec 2001; 148: 319.

5.- Armstrong R, Davie J, Hedger R S. Foot and mouth disease in man. Br Med J 1967; 4: 529-30.

6.- Bohn H O. Foot and mouth disease in man. Z Allgemeinmed 1972; 48: 149-51.

7.- Capella G L. Foot and mouth disease in human beings. Lancet 2001; 358 (9290): 1374.

8.- David W, Brown G. Foot and mouth disease in human beings. Lancet 2000; 357 (9267): 1463.

9.- Dlugosz H. Foot and mouth disease in man. Br Med J 1968; 1: 251-2.

10. - Casas Olascoaga, Gómez R I, Rosenberg F J, Augé De Mello J P, Astudillo V, Magallanes
N. 1999. Fiebre Aftosa. Editora Atheneu.

11.- Eissner G, Bohn H O, Julick E. A human case of foot and mouth disease. Ger Med Mon 1967; 12: 271-3.

12.- Rasmussen E S. Foot and mouth disease in man. Report of a case and some serologic observations. Ugeskr Laeger 1968; 130: 1619-21.

13.- Meléndez L. Aislamiento e identificación del virus de la fiebre aftosa procedente de vesículas de la epidermis de un ser humano. Bol Of San Pan 1961; 100: 135-7.

14.- Acha P N, Szyfres B. Fiebre aftosa. En: Zoonosis y enfermedades transmisibles comunes al hombre y a los animales. Ed Washington DC, OPS 1968; p. 394-407. (Publicaciones Científicas, 503).

15.- Hyslop N S. Transmission of the virus of foot and mouth disease between animals and man. Bull World Health Org 1973; 49: 557 85.

16.- Korotich A S, Vasil'chenko A A, Sobko A I, Sokolov L N, Prokhorov V N. Foot and mouth disease in man. $\mathrm{Zh}$ Mikrobiol Epidemiol Immunobiol 1974; 2: 132-5.

17.- Jebavy Z. Foot and mouth disease in people. Cesk Stomatol 1976; 76: 200-3.

18.- Prempeh H, Smith R, Miller B. Foot and mouth disease: the human consequences. $\mathrm{Br}$ Med J 2001; 10: 565-6.

19.- Simmons N, Feldman R. If foot and mouth disease were a disease of human beings? Lancet Infect Dis 2001; 1: 75-6.

20.- van der Poel W H. Transmission of the foot and mouth disease virus through milk and meat products is not a threat for human health. Tijdscher Diergeneeskd 2001; 126: 285-6.

21.- Chan L G, Parashar U D, Lye M S, Zaki S R, Ong F G, Alexander J P, et al. Deaths of children during an outbreak of hand, foot and mouth disease in Sarawak, Malyasia: clinical and pathological characteristics of the disease. Clin Infect Dis 2000; 31: 67883.

22.- Shieh W, Jungs S M, Hsueh C, Kuo T T, Mounts A, Parashar U D, et al. Pathologic studies of fatal cases in outbreaks of hand, foot and mouth disease. Taiwan. Emerg Infect Dis 2001; 7: 146-8.

23.- Bauer K. Foot and mouth disease as zoonosis. Arch Virol (Suppl) 1997; 13: 95-7.

24.- Schrijver R S, Van Oischot J T, Dekker A, Schneider M M, Van Knapen F, Kimman T G. Foot and mouth disease is not a zoonosis. Tijdschr Diergeneekd 1998; 123: 750. 